\title{
No Apparent Impact of Meal Glycemic Index on Postprandial Lipid Response in Lean and Abdominally Obese Women
}

\author{
Kathryn Silliman ${ }^{1, *}$, John Mahoney ${ }^{2}$, Vanessa Michels ${ }^{1}$ and Troy Miles ${ }^{2}$ \\ ${ }^{1}$ Department of Nutrition and Food Sciences, California State University, Chico CA 95929-0002, USA \\ ${ }^{2}$ Department of Biological Sciences, California State University, Chico CA 95929-0515, USA
}

\begin{abstract}
The objective of this study was to investigate effects of a low and high glycemic index (GI) meal and abdominal obesity on postprandial lipid response. Twenty-six obese and 15 lean women consumed a high (66) or low GI (44) meal of similar macronutrient and energy composition and then returned one to two weeks later to consume the other meal. Blood samples $(0,1,3,5$ hour) were analyzed for insulin; free fatty acids; and total-, and chylomicron (CM)triglycerides. Both groups (obese and lean, respectively) had significantly $(\mathrm{p}<0.05)$ greater insulin AUCs after consuming the high GI meal ( $1264 \pm 889$ vs. $653 \pm 431 \mathrm{pmol} / \mathrm{L})$ than the low GI meal ( $764 \pm 708$ vs. $320 \pm 243)$. Meal type had no effect on the AUC for total-, or CM-triglyceride. Obese subjects had higher postprandial insulin $(\mathrm{p}<0.05)$, free fatty acid $((\mathrm{p}<0.05)$, total- $(\mathrm{p}=0.06)$ and CM-triglycerides $(\mathrm{p}<0.05)$. QUICKI, an index of insulin sensitivity, was used to compare subjects from the upper and lower quartiles. Subjects with a QUICKI $\leq 0.31(\mathrm{n}=10)$ had higher AUCs for insulin (3-fold) and triglyceride (2.5-fold); and TG/HDL-C (3-fold) than subjects with a QUICKI $\geq 0.35(\mathrm{n}=9)$. These later subjects had a slightly reduced triglyceride AUC after the high GI meal $(\mathrm{p}=0.12)$. Women with abdominal obesity and insulin resistance have greater postprandial triglyceride response. The high GI meal increased the postprandial insulin response but appeared to have no effect on postprandial lipids. In this study, single meal GI had no effect on postprandial lipids but more research is needed, both short- and long-term studies.
\end{abstract}

Keywords: Glycemic index, obesity, postprandial lipemia, chylomicrons.

\section{INTRODUCTION}

The glycemic index (GI) is measured by monitoring the two hour blood glycemic response to 50 grams of carbohydrate of a test food and expressed as a percent of that elicited by 50 grams of glucose [1]. Typical American foods such as highly refined breads and breakfast cereals, and potatoes have higher GIs than pasta, unprocessed cereals, legumes, dairy products and many types of fruits and vegetables $[2,3]$. There are GIs published for over 2,400 foods [4]. Glycemic load (GL) was a term introduced in the late 1990's because the glycemic response of a food is dependent on the type and total amount of carbohydrate. It is defined as the product of the GI of a food and the amount of available carbohydrate in a serving $[5,6]$. The concepts of GI and GL can be applied, not only to single foods, but to mixed meals or whole diets $[6,7]$.

Diets with a greater GL and GI are associated with increased risk of type 2 diabetes $[6,8]$ and cardiovascular disease [7-10], presumably due to exaggerated postprandial glycemia. However, not all studies find disease associations [11-13]. In addition to alterations in blood glucose, GI and GL may influence the risk of cardiovascular disease by raising plasma triglyceride [14-19] and reducing HDLcholesterol [14, 15, 18-23], particularly in obese individuals [16-18].

\footnotetext{
*Address correspondence to this author at the Department of Nutrition and Food Sciences, California State University, Chico CA 95929-0002, USA; Tel/Fax: 530-898-6245/6805; E-mail: KSilliman@csuchico.edu
}

Lipid risk factors are determined in the fasting state; however, humans spend much of life in the postprandial state, which is characterized by a rise in triglyceride-rich lipoproteins. Zilversmit first proposed that postprandial hyperlipidemia played a role in atherogenesis [24]. More recent evidence indicates it may be linked with heart disease [25].

Most studies on the short-term impact of meal GI measured the glucose and/or insulin response, while only a few measured blood lipid response [17, 26-29]. Harbis, et al., [17] found that a meal with rapidly digested carbohydrate compared to a meal with slowly digested carbohydrate increased postprandial triglyceride response. In contrast, Perälä, et al., [29] and Bukkapatnam, et al., [28] found a greater postprandial triglyceride response after a low GI meal compared to a high GI meal. One study reported that the triglyceride level after a high GI lunch was lower four hours after consuming a low GI meal breakfast than a high GI breakfast [27]. Yet another found no difference in day-long (8 hour) postprandial triglyceride response [26]. However, none of the studies measured chylomicron (CM)triglyceride response. Due to the limited number of studies of the short-term effect of GI on lipid response, with inconsistent findings, the primary purpose of the present study was to investigate the effects of meal glycemic index on the postprandial lipid and CM-triglyceride response. Prior research has shown that obesity, particularly abdominal obesity, is associated with dyslipidemia and insulin resistance [30] and that obese individuals are prone to postprandial lipemia [31-34]. Thus we also explored 
postprandial lipid response in two groups of subjects, lean and obese. This study tests the hypothesis that a high glycemic index meal results in a greater postprandial lipid response than a low glycemic index meal.

\section{MATERIALS AND METHODS}

\section{Subjects}

Subjects were recruited from the University and community of Chico, California using fliers and advertisements. The study was approved by the Human Subjects in Research Committee, California State University, Chico and subjects provided written consent. Subjects were 26 healthy women with abdominal obesity [BMI $\geq 30$ with a waist circumference $\geq 88.9 \mathrm{~cm}$ ) and 15 healthy women of a normal (referred to as "lean") size (BMI 20-25 with a waist circumference $<88.9 \mathrm{~cm}$ ) using criteria established by NIH [35].

\section{Study Design and Test Meals}

Using a crossover design each subject consumed two breakfast meals, one low glycemic index meal (44) and one high GI meal (66) as shown in Table 1 after a 12 hour overnight fast. Subjects were instructed to avoid alcohol or participate in heavy physical activity in the 48 hours prior to testing and to avoid consuming a fat-rich meal the evening prior to testing. Both meals were of a similar composition: 775 calories $(3244 \mathrm{~J}), 98 \mathrm{~g}$ of carbohydrate, $32 \mathrm{~g}$ fat, and 26 $\mathrm{g}$ protein. The order in which subjects received the meals was staggered (subject 1 low GI first meal, subject 2 high GI first meal, etc.) with subject recruitment. The period between test meals ranged from 5-14 day due to subject and facility availability. Venous blood samples were collected prior to each test meal (time 0) and then at 1 hour, 3 hour, and 5 hour after completion of the meal. Subjects were given 20 minutes to consume the test meals similar to other studies measuring postprandial lipid response [17, 36-38]. Plasma or serum samples were frozen at $-70^{\circ} \mathrm{C}$ until analyses.

\section{Analytical Procedures}

Fasting plasma or serum samples were analyzed for glucose, total cholesterol, high density lipoproteincholesterol (HDL), and apolipoprotein C-3. Fasting and postprandial plasma or serum samples were analyzed for insulin,

Table 1. Test Meals

\begin{tabular}{|c|c|c|c|c|c|c|}
\hline Test Meals & Carbohydrate (g) & Food GI & Glycemic Load ${ }^{\mathrm{a}}$ & Energy (kcal) & Fat (g) & Protein (g) \\
\hline Crispix (44 g/1 1⁄2 C) & 38 & .87 & 33 & 164 & 0 & 3 \\
\hline whole milk (244 g / 1 C) & 13 & .27 & 3.5 & 160 & 8 & 8 \\
\hline plain white bagel $(55 \mathrm{~g} / 1 / 2)$ & 29 & .72 & 20.9 & 145 & 1 & 5 \\
\hline peanut butter (32 g/2 tbsp) & 6 & .14 & 0.8 & 190 & 16 & 8 \\
\hline liquid cream (21 g/11/4 tbsp) & 0 & & & 62 & 6 & 0 \\
\hline \multicolumn{7}{|l|}{ decaf coffee or tea $(244 \mathrm{~g} / 1 \mathrm{C})$} \\
\hline All bran $(15 \mathrm{~g} / 1 / 4 \mathrm{C})$ & 11 & .42 & 4.6 & 40 & 0 & 2 \\
\hline whole milk (244 g/1 C) & 13 & .27 & 3.5 & 160 & 8 & 8 \\
\hline green apple (130 g/1 med) & 20 & .38 & 7.6 & 77 & 0 & 0 \\
\hline mixed-grain bread (64 g/2 sl) & 26 & .53 & 13.8 & 200 & 6 & 8 \\
\hline peanut butter (20 g/11/4 tbsp) & 4 & .14 & 0.6 & 120 & 10 & 5 \\
\hline liquid cream (15 g/1 tbsp) & 0 & & & 52 & 5 & 0 \\
\hline \multicolumn{7}{|l|}{ decaf coffee or tea $(244 \mathrm{~g} / 1 \mathrm{C})$} \\
\hline Total & 97 & & $44^{\mathrm{d}}$ & 779 & 33 & 28 \\
\hline
\end{tabular}

${ }^{\mathrm{a}}$ Glycemic Load $=$ carbohydrate $(\mathrm{g}) \mathrm{x}$ food glycemic index (expressed as a decimal)

${ }^{b}$ Meal composition (\% of total calories): $36 \%$ fat; $13 \%$ protein; $51 \% \mathrm{CHO}$

${ }^{\mathrm{c}}$ Meal composition (\% of total calories): $38 \%$ fat; $14 \%$ protein; $50 \% \mathrm{CHO}$

${ }^{\mathrm{d}}$ Meal GI = (total glycemic load of meal/total carbohydrate of meal) $\mathrm{x} 100$ 
free fatty acids, total triglyceride, and chylomicron (CM)triglyceride. Glucose was analyzed using a kit from Sigma (St Louis MO, 17-25). Insulin was analyzed using an enzyme-linked immunoassay (ALPCO, Windham NH, 00810-1113-01). Free fatty acids were analyzed using a colorimetric assay (Wako, Richmond VA, 994-75409).

Plasma was preserved with phenylmethylsulfonyl fluoride $(10 \mu \mathrm{M})$ and aprotinin $(50 \mathrm{KIU} / \mathrm{ml})$ prior to lipoprotein separation and lipid analysis. The $\mathrm{CM}$ fraction was isolated from fresh plasma according to the method described by Nelson [39]. HDL was isolated from fresh plasma using a phosphotungstic acid, magnesium chloride precipitation method (Sigma, St Louis MO, 352-4). These lipoprotein fractions were then frozen prior to lipid analysis. Total triglyceride and CM-triglyceride were analyzed using a kit from Sigma (St Louis MO, 352-4) and Wako (Richmond VA). Total cholesterol and HDL-cholesterol were analyzed using a kit from Sigma (St Louis MO, 401-25P). Apolipoprotein C-3 was analyzed using an immunoturbidity method from Wako (Richmond VA, 411-35801).

\section{Statistical Analysis}

IBM SPSS version 19.0 for Windows (2010, IBM Inc, Armonk, New York) was used to analyze the data. The trapezoidal method was used to calculate area under the curve (AUC) for 0-5 hour blood insulin, total triglyceride, and CM-triglyceride data [1]. Paired t-tests were used to evaluate dietary (high versus low GI meal) differences in AUC data and differences in blood values at specific time point. A repeated measure ANOVA was used to evaluate the impact of obesity (BMI) and diet (main effects). Insulin sensitivity in the current study was based on quantitative insulin sensitivity check index (QUICKI), reported to be a simple, robust and accurate index of insulin sensitivity [40]. Since fasting glucose and insulin were measured twice, the mean values were used in calculating the QUICKI $=1 /[\log$ (fasting insulin, $\mu \mathrm{U} / \mathrm{ml}$ ) $+\log$ (fasting glucose, $\mathrm{mg} / \mathrm{dl}$ )] Subjects were separated into insulin insensitive [lower quartile QUICKI $\leq 0.31 \quad(\mathrm{n}=10$, all obese $)]$ and insulin sensitive [upper quartile QUICKI $\geq 0.35(\mathrm{n}=9,8$ lean and 1 obese)] groups. T-tests were used to evaluate differences between groups and paired t-tests were used to evaluate dietary effects.

\section{RESULTS}

Age, anthropometric and lipid values of lean and obese subjects are shown in Table 2. Obese subjects were heavier and had greater waist circumference and slightly lower HDL-cholesterol $(\mathrm{p}=0.05)$ than lean subjects.

Obese subjects had significantly higher postprandial concentrations of insulin than lean subjects (Table 3). Insulin was elevated one hour after consuming the high GI meal in both groups and it remained elevated through hour three in the obese group. The insulin AUC was significantly greater after consumption of the high GI meal in both groups. Obese subjects had significantly higher concentrations of CMtriglyceride and free fatty acids. Concentrations of total triglyceride were slightly elevated in obese subjects. Meal GI appeared to have no effect on the AUC for total triglyceride in either group while the CM-triglyceride AUC appeared to be slightly, but not significantly $(p=0.11)$, greater after consumption of the low GI meal in obese subjects.

Insulin insensitive subjects had significantly greater area under the curves (AUCs) for total triglyceride and insulin and significantly elevated ratio of triglyceride/HDLcholesterol than insulin sensitive subjects (Table 4). Insulin sensitive subjects had slightly, but not significantly $(\mathrm{p}=0.12)$, lower AUC for total triglyceride after the high GI meal than low GI meal.

\section{DISCUSSION}

Insulin response ( 5 hour AUC) was significantly greater after the high GI meal in both lean and obese groups. This postprandial insulin effect of a high glycemic index meal is well documented in the literature [27-29, 41, 42]. Obese subjects also had a greater insulin response to meals than lean subjects. Obese insulin insensitive subjects had a 2.5 fold higher total triglyceride AUC than insulin sensitive subjects. Similarly, Perälä, et al., [29] who recruited both overweight and normal weight subjects with normal and impaired glucose tolerance, found the highest insulin

Table 2. Age, Anthropometric, and Lipid Levels of Lean and Obese Subjects

\begin{tabular}{|l|c|c|}
\hline & Lean n=15 & Obese n=26 \\
\hline \hline Age $($ years $)$ & $26 \pm 8$ & $27 \pm 9$ \\
\hline Height $(\mathrm{cm})$ & $163.8 \pm 6.6$ & $164.8 \pm 7.6$ \\
\hline Weight $(\mathrm{kg})$ & $60.7 \pm 5.3$ & $98.1 \pm 18.1^{*}$ \\
\hline BMI $\left(\mathrm{kg} / \mathrm{m}^{2}\right)$ & $22.6 \pm 1.6$ & $35.9 \pm 5.3^{*}$ \\
\hline Waist circumference $(\mathrm{cm})$ & $81.3 \pm 5.6$ & $111.8 \pm 13^{*}$ \\
\hline Total triglyceride $(\mathrm{mmol} / \mathrm{L})$ & $0.79 \pm 0.39$ & $1.12 \pm 0.92$ \\
\hline Total cholesterol $(\mathrm{mmol} / \mathrm{L})$ & $4.84 \pm 1.20$ & $5.10 \pm 1.07$ \\
\hline HDL-cholesterol $(\mathrm{mmol} / \mathrm{L})$ & $1.48 \pm 0.98$ & $1.14 \pm 0.49$ \\
\hline
\end{tabular}

Values are mean \pm SD

t-test for group effect, $* \mathrm{p}<0.05$ 
Table 3. Impact of High and Low Meal Glycemic Index (GI) and Obesity on Insulin, Triglyceride, Chylomicron (CM) Triglyceride, and Free Fatty Acids (FFA) at Individual Time Points and Area Under the Curve (AUC)

\begin{tabular}{|c|c|c|c|c|c|}
\hline & $\mathbf{0}$ & 1 hour & 3 hour & 5 hour & AUC \\
\hline \multicolumn{6}{|c|}{ Obese $(n=26)$} \\
\hline \multicolumn{6}{|c|}{ Insulin $(\mathrm{pmol} / \mathrm{L}) \#$} \\
\hline High GI & $139 \pm 139$ & $715 \pm 493^{*}$ & $326 \pm 250^{*}$ & $125 \pm 104$ & $1264 \pm 889^{*}$ \\
\hline Low GI & $118 \pm 70$ & $493 \pm 389$ & $222 \pm 181$ & $111 \pm 70$ & $764 \pm 708$ \\
\hline \multicolumn{6}{|c|}{ Triglyceride $(\mathrm{mmol} / \mathrm{L}) \# \#$} \\
\hline High GI & $1.08 \pm 0.87$ & $1.42 \pm 1.07$ & $1.71 \pm 1.48$ & $1.36 \pm 1.17$ & $2.08 \pm 2.15$ \\
\hline Low GI & $1.14 \pm 0.97$ & $1.35 \pm 0.91$ & $1.77 \pm 1.22$ & $1.50 \pm 1.17$ & $1.97 \pm 1.33$ \\
\hline \multicolumn{6}{|c|}{ CM-triglyceride $(\mathrm{mmol} / \mathrm{L}) \#$} \\
\hline High GI & $3.81 \pm 2.19$ & $5.66 \pm 3.67$ & $5.84 \pm 3.06$ & $4.78 \pm 2.92$ & $8.22 \pm 6.08$ \\
\hline Low GI & $3.67 \pm 3.12$ & $5.24 \pm 3.83$ & $6.68 \pm 4.75$ & $5.41 \pm 4.70$ & $10.37 \pm 7.36$ \\
\hline \multicolumn{6}{|l|}{ FFA $(\mathrm{mM}) \#$} \\
\hline High GI & $0.46 \pm 0.04$ & $0.29 \pm 0.03 *$ & $0.32 \pm 0.03$ & $0.58 \pm 0.25$ & \\
\hline Low GI & $0.47 \pm 0.02$ & $0.25 \pm 0.02$ & $0.41 \pm 0.07$ & $0.70 \pm 0.10$ & \\
\hline \multicolumn{6}{|l|}{ Lean $(n=15)$} \\
\hline \multicolumn{6}{|c|}{ Insulin $(\mathrm{pmol} / \mathrm{L})$} \\
\hline High GI & $56 \pm 28$ & $347 \pm 278^{*}$ & $160 \pm 139$ & $49 \pm 28$ & $653 \pm 431^{*}$ \\
\hline Low GI & $70 \pm 28$ & $208 \pm 139$ & $111 \pm 76$ & $56 \pm 28$ & $320 \pm 243$ \\
\hline \multicolumn{6}{|c|}{ Triglyceride $(\mathrm{mmol} / \mathrm{L})$} \\
\hline High GI & $0.77 \pm 0.54$ & $1.01 \pm 0.67$ & $1.19 \pm 0.89$ & $1.02 \pm 0.67$ & $1.50 \pm 1.29$ \\
\hline Low GI & $0.81 \pm 0.32$ & $0.93 \pm 0.35$ & $1.31 \pm 0.47$ & $1.04 \pm 0.35$ & $1.39 \pm 0.75$ \\
\hline \multicolumn{6}{|c|}{$\mathrm{CM}$-triglyceride $(\mathrm{mmol} / \mathrm{L})$} \\
\hline High GI & $2.51 \pm 2.26$ & $4.00 \pm 3.24$ & $4.49 \pm 3.67$ & $3.25 \pm 2.34$ & $7.15 \pm 5.50$ \\
\hline Low GI & $2.51 \pm 1.33$ & $3.90 \pm 1.88$ & $5.20 \pm 2.42$ & $3.66 \pm 1.48$ & $8.64 \pm 5.85$ \\
\hline \multicolumn{6}{|l|}{ FFA (mM) } \\
\hline High GI & $0.48 \pm 0.07$ & $0.23 \pm 0.02$ & $0.26 \pm 0.03$ & $0.45 \pm 0.06$ & \\
\hline Low GI & $0.47 \pm 0.05$ & $0.23 \pm 0.02$ & $0.27 \pm 0.02$ & $0.47 \pm 0.04$ & \\
\hline
\end{tabular}

Values are mean \pm SD

${ }^{*} \mathrm{p}<0.05$ (paired t-test for diet effect)

$\# p<0.05, \# \# p=0.06$ (ANOVA, main effect: obesity)

response to both GI meals (high and low) occurred in the overweight subjects with impaired glucose tolerance.

In the present study obese subjects had slightly higher postprandial triglyceride levels and significantly higher postprandial CM-triglyceride levels than lean subjects after consuming high carbohydrate meals (50\% of total calories) with $31-33 \mathrm{~g}$ of fat. Our results may vary from others due to the number of grams of fat in the meals and age (young) and health status of subjects. Most of the previous research comparing the postprandial lipid response between obese and lean subjects used meals with fat loads ranging from 40 to over $100 \mathrm{~g}$ of fat $[33,34,36]$. Similar to the present study, the total triglyceride $[33,34,36]$ and chylomicron-triglyceride responses [33,36] were greater in obese subjects or obese subjects with central obesity. Dallongeville, et al., [37] gave subjects a carbohydrate load (166 g carbohydrate, $38 \mathrm{~g}$ protein) and found that the 9 hour total triglyceride response and triglyceride-rich lipoproteins were greater in morbidly obese subjects. In contrast, Guerci, et al., [38] noted no difference in total triglyceride or CM-triglyceride responses between obese or normal weight subjects, but it should be noted that both obese and normal weight subjects had normal fasting triglyceride levels.

Meal GI appeared to have no effect on the postprandial triglyceride response in either group while the CMtriglyceride response appeared to be slightly $(\mathrm{p}=0.11)$ higher after consumption of the low GI meal in the obese subjects. This later finding may be the result of the reduced insulin response to the low GI meal $(60 \%$ of response of high GI meal) which might delay the clearance of chylomicrons. Perälä, et al., [29] noted a low GI meal produced a greater total triglyceride response (5 hour) than a high GI meal for 
Table 4. Impact of Insulin Sensitivity on Total Triglyceride (TG) and Insulin Area Under the Curve (AUC), TG/HDL-C Ratio, and Apolipoprotein (Apo) C-3

\begin{tabular}{|l|c|c|c|}
\hline & Insulin Sensitive n=9 & Insulin Insensitive n=10 & P Value ${ }^{\mathbf{a}}$ \\
\hline \hline AUC TG (mmol/L) & $1.04 \pm 0.41$ & $2.59 \pm 2.17$ & 0.05 \\
\hline AUC Insulin (pmol/L) & $528 \pm 347$ & $1541 \pm 896$ & 0.01 \\
\hline TG/HDL-C & $1.2 \pm 0.5$ & $3.5 \pm 2.8$ & 0.03 \\
\hline Apo C-3 (mg/dL) & $9.3 \pm 1.5$ & $10.4 \pm 3.3$ & 0.35 \\
\hline AUC TG (mmol/L) & & $3.02 \pm 3.11^{* *}$ & 0.06 \\
High GI & $0.88 \pm 0.31^{*}$ & $2.17 \pm 1.92$ & 0.17 \\
Low GI & $1.21 \pm 0.63$ & \\
\hline
\end{tabular}

Values are mean \pm SD

${ }^{a}$ t-test for group effect

paired t-test for diet effect, ${ }^{*} \mathrm{p}=0.12 ; * * \mathrm{p}=0.37$

both normal weight and obese subjects, possibly due to a fructose-sweetened juice in the low GI meal. Bukkapatnam, et al., [28] also found that a low glycemic index meal produced a greater increase in postprandial triglyceride. In contrast, Harbis, et al., [17] reported the 6 hour triglyceride response was greater after consumption of a wheat flakes meal with more rapidly available carbohydrate. Like our study, Byrnes, et al., [26] found no difference in 8 hour postprandial triglyceride between high and low GI meals. Variations in findings could be due to differences in mean BMI of subjects, degree of insulin resistance among obese subjects, age, time intervals for measuring lipid response, and/or caloric and macronutrient content of meals.

Abdominal obesity is associated with insulin resistance [30]. In insulin resistance, insulin fails to suppress the release of free fatty acids from adipose tissue leading to excess lipolysis and elevated free fatty acids [30]. Obese subjects in the current study had significantly higher free fatty acids than lean subjects which agree with previous research $[43,44]$. We found little effect of meal GI on the free fatty acid response. This is similar to findings of Bukkapatnam, et al., [28] and Perälä, et al., [29]. Our findings are in contrast to Galgani, et al., [42] and Diaz, et al., [45] who noted that serum free fatty acids were elevated four and five hours after consumption of a low GI meal compared to a high GI meal. The authors speculate that the higher insulin levels released with the high GI meal enhance clearance of free fatty acids and/or enhance suppression the release of free fatty acids $[42,45]$.

The insulin resistance associated with obesity may contribute to elevated triglyceride due insulin's failure to activate lipoprotein lipase [30]. Apo C-3, a protein produced by the liver, inhibits lipoprotein lipase. Elevated levels of apo C-3 are associated with higher levels of triglyceride through reduced clearance of triglyceride-rich lipoproteins $[46,47]$. Apo C-3 was slightly higher, but not significantly, in the insulin resistant subjects. While meal GI had no effect on the postprandial triglyceride response in the insulin resistant group, the postprandial triglyceride response after the high GI meal was slightly reduced in those subjects who were insulin sensitive compared to the low GI meal suggesting a greater clearance of postprandial fats due to the enhanced insulin response. Despite the 3-fold greater insulin response to meals in the obese-insulin insensitive subjects, postprandial triglyceride response was 2.5 fold higher than insulin sensitive subjects possibly due to reduced clearance of triglyceride-rich particles [30].

There were several limitations to this study. Freezing of the plasma samples could impact the lipid results we obtained [48]. Plasma triglyceride levels are also subject to greater physiological variation than cholesterol levels [49]. We did not require subjects to keep diet records in the days prior to consumption of test meals nor require they follow a standard diet. Thus we were not able to control for possible variations in dietary intake. There was a range of 5 to 14 days in between test meals. It would have been ideal to have a set number of days test meals. The difference in GI between what we defined as high versus low may not have been large enough to impact postprandial lipids. The postprandial response was only measured for single meals, blood was sampled infrequently, and the sample size was small. The strengths of the study were that we measured chylomicron-triglyceride, unlike other short-term studies on glycemic index. The meals contained foods that are typical of an American diet, were not excessive in calories, and had a macronutrient composition reflective of dietary guidelines for total fat, protein and carbohydrate. Unlike other studies we did not add fruit juice [29] or glucola [28] in order to increase the GI of the high GI meal. Subjects were healthy and female eliminating any potential influence of gender or metabolic abnormalities. The concept of glycemic index remains controversial and may have limited utility for understanding nutritional effects.

\section{CONCLUSION}

Meal GI appeared to have no effect on the postprandial lipid response. Both obese and lean subjects had elevated postprandial insulin after the high GI meal. The long-term impact of this acute effect is unknown. Clearly, more research is needed on the acute and long-term effects of meal and diet glycemic index in healthy and diseased populations. 


\section{ACKNOWLEDGEMENTS}

The authors wish to thank Ann Morrissey, MD and Ken Logan, MD and the staff at the Student Health Center, for their contributions to this research; David Philhour for statistical help; and the many undergraduate students of the Departments of Biological Sciences and Nutrition and Food Sciences who worked on this project. This research was supported by the National Institutes of Health Grant No. DK58602-01A1 and the College of Natural Sciences, California State University, Chico.

\section{CONFLICT OF INTEREST}

The author(s) confirm that this article content has no conflicts of interest.

\section{REFERENCES}

[1] Joint FAO/WHO expert consultation. Carbohydrates in human nutrition. April 14-18, 1997. FAO Food and Nutrition Paper 66, FAO, Rome, Italy 1998.

[2] Ludwig DS. The glycemic index. Physiological mechanisms relating to obesity, diabetes, and cardiovascular disease. JAMA 2002; 287: 2414-23

[3] Brand-Miller J, Foster-Powell K. Diets with a low glycemic index: From theory to practice. Nutr Today $1999 ; 34: 64-72$

[4] Atkinson FS, Foster-Powell K, Brand-Miller J. International table of glycemic index and glycemic load values: 2008. Diabetes Care 2008; 31: 2281-3.

[5] Sheard NF, Clark NG, Brand-Miller J, et al. Dietary carbohydrate (amount and type) in the prevention and management of diabetes. Diabetes Care 2004; 27: 2266-71.

[6] Salmeron J, Ascherio A, Rimm EB, et al. Dietary fiber, glycemic load, and risk of NIDDM in men. Diabetes Care 1997; 20: 545-50.

[7] Liu S, Willett WC, Stampfer MJ, et al. A prospective study of dietary glycemic load, carbohydrate intake, and risk of coronary heart disease in US women. Am J Clin Nutr 2000; 71: 1455-61.

[8] Barclay AW, Petocz P, McMillan-Price J, et al. Glycemic index, glycemic load, and chronic disease risk - a meta-analysis of observational studies. Am J Clin Nutr 2008; 87: 627-37.

[9] Mursu J, Virtanen JK, Rissanen TH, et al. Glycemic index, glycemic load, and the risk of acute myocardial infarction in Finnish men: The Kuopio Ischaemic Heart Disease Risk Factor Study. Nutr Metab Cardiovasc Dis 2011; 21: 144-9.

[10] Burger KN, Beulens JW, Boer JM, Spijkerman AM, van der A DL. Dietary glycemic load and glycemic index and risk of coronary heart disease and stroke in Dutch men and women: the EPICMORGEN study. PLoS One 2011; 6: e25955. doi:10.1371/journal. pone.0025955.

[11] Levitan EB, Mittleman MA, Hakansson N, Wolk A. Dietary glycemic index, dietary glycemic load, and cardiovascular disease in middle-aged and older Swedish men. Am J Clin Nutr 2007; 85: 1521-6.

[12] van Dam RM, Visscher AW, Feskens EJ, Verhoef P, Kromhout D. Dietary glycemic index in relation to metabolic risk factors and incidence of coronary heart disease: the Zutphen Elderly Study. Eur J Clin Nutr 2000; 54: 726-31.

[13] Similä ME, Valsta LM, Kontto JP, Albanes D, Virtamo J. Low-, medium- and high-glycaemic index carbohydrates and risk of type 2 diabetes in men. Br J Nutr 2011; 105: 1258-64.

[14] Ma Y, Li Y, Chiriboga DE, et al. Association between carbohydrate intake and serum lipids. J Am Coll Nutr 2006; 25: 155-63.

[15] Murakami K, Sasaki S, Takahashi Y, et al. Dietary glycemic index and load in relation to metabolic risk factors in Japanese female farmers with traditional dietary habits. Am J Clin Nutr 2006; 83: 1161-9.

[16] Ebbeling CB, Leidig MM, Sinclair KB, Seger-Shippe LG, Feldman HA, Ludwig DS. Effects of an ad libitum low-glycemic load diet on cardiovascular disease risk factors in obese young adults. Am J Clin Nutr 2005; 81: 976-82.
[26] Brynes AE, Mark Edwards C, Ghatei MA, et al. A randomized four-intervention crossover study investigating the effect of carbohydrates on daytime profiles of insulin, glucose, nonesterified fatty acids and triacylglycerols in middle-aged men. $\mathrm{Br} \mathrm{J}$ Nutr 2003; 89: 207-18.

[27] Liljeberg H, Bjorck I. Effects of a low-glycaemic index spaghetti meal on glucose tolerance and lipaemia at a subsequent meal in healthy subjects. Eur J Clin Nutr 2000; 54: 24-8.

[28] Bukkapatnam RN, Berglund L, Anuurad E, et al. Postprandial metabolic responses to dietary glycemic index in hypercholesterolemic postmenopausal women. Prev Cardiol 2010; 13: 29-35.

[29] Perälä MM, Hätönen KA, Virtamo J, et al. Impact of overweight and glucose tolerance on postprandial responses to high- and lowglycaemic index meals. Br J Nutr 2011; 105: 1627-34.

[30] Franssen R, Monajemi H, Stroes ES, Kastelein JJ. Obesity and dyslipidemia. Med Clin North Am 2011; 95: 893-902.

[31] Otokozawa S, Aia M, Diffenderfer MR, et al. Fasting and postprandial apolipoprotein B-48 levels in healthy, obese, and hyperlipidemic subjects. Metabolism 2009; 58: 1536-42.

[32] Couillard C, Bergeron N, Pascot A, et al. Evidence for impaired lipolysis in abdominally obese men: postprandial study of apolipoprotein B-48- and B-100-containing lipoproteins. Am J Clin Nutr 2002; 76: 311-8.

[33] Mekki N, Christofilis MA, Charbonnier M, et al. Influence of obesity and body fat distribution on postprandial lipemia and triglyceride-rich lipoproteins in adult women. J Clin Endocrinol Metab 1999; 84: 184-91

[34] Vansant G, Mertens A, Muis E. Determinants of postprandial lipemia in obese women. Int J Obes 1999; 23: 14-21.

[35] National Institutes of Health. Clinical guidelines on the identification, evaluation, and treatment of overweight and obesity in adults. The evidence report. NIH Publication No. 98-4083, Bathesda: US Department of Health and Human Services; September 1998.

[36] Jensen J, Bysted A, Dawids S, Hermansen K, Gunhild Hølmer G. The effect of palm oil, lard, and puff-pastry margarine on postprandial lipid and hormone responses in normal-weight and obese young women. Br J Nutr 1999; 82: 469-79.

[37] Dallongeville J, Harbis A, Lebel P, et al. The plasma and lipoprotein triglyceride postprandial response to a carbohydrate tolerance test differs in lean and massively obese normolipidemic women. J Nutr 2002; 132: 2161-6.

[38] Guerci B, Verges B, Durlach V, Hadjadi S, Drouin P, Paul JL. Relationship between the altered postprandial lipemia and insulin resistance in normolipidemic and normoglucose tolerant obese patients. Int J Obes Relat Metab Disord 2000; 24: 468-78. 
[39] Nelson G. Blood lipids and lipoproteins: Quantitation, composition, and metabolism. New York: John Wiley and Sons 1972.

[40] Muniyappa R, Lee S, Chen H, Quon MJ. Current approaches for assessing insulin sensitivity and resistance in vivo: advantages, limitations, and appropriate usage. Am J Physiol Endocrinol Metab 2008; 294: E15-26.

[41] Wolever T, Yang M, Zeng XY, Atkinson F, Brand-Miller J. Food glycemic index, as given in glycemic index tables, is a significant determinant of glycemic responses elicited by composite breakfast meals. Am J Clin Nutr 2006; 83: 1306-12.

[42] Galgani J, Aguirre C, Diaz E. Acute effect of meal glycemic index and glycemic load on blood glucose and insulin response in humans. Nutr J 2006; 5: 22.

[43] Guo Z, Hensrud DD, Johnson M, Jensen M. Regional postprandial fatty acid metabolism in different obesity phenotypes. Diabetes 1999; 48: 1586-92.

[44] Herranz L, Zapata A, Crande C, Megia A, Pallardo LF. Body fat distribution, insulin mediated suppression of non-esterified fatty acids and plasma triglycerides in obese subjects. Horm Metab Res 1998; 30: 141-5.

[45] Diaz EO, Galgani JE, Aguirre CA, Atwater IJ, Burrows R. Effect of glycemic index on whole-body substrate oxidation in obese women. Int J Obes 2005; 29: 108-14.

[46] McConathy WJ, Gesquiere JC, Bass H, Tartar A, Fruchart JC, Wang CS. Inhibition of lipoprotein lipase activity by synthetic peptides of apolipoprotein C-III. J Lipid Res 1992; 33: 995-1003.

[47] Ginsberg HN, Le NA, Goldberg IJ, et al. Apolioprotein B metabolism in subjects with deficiency of apolipoproteins C-III and AI. Evidence that apolipoproteins C-III inhibits catabolism of triglyceride-rich lipoproteins by lipoprotein lipase in vivo. J Clin Invest 1986; 78: 1287-95.

[48] Zivkovic AM, Wiest MM, Nguyen UT, Davis R, Watkins SM, German JB. Effects of sample handling and storage on quantitative lipid analysis in human serum. Metabolomics 2009; 5: 507-16.

[49] Warnick GR, Albers, JJ. Physiological and analytical variation in cholesterol and triglycerides. Lipids 1976; 11: 203-8.

(C) Silliman et al.; Licensee Bentham Open

This is an open access article licensed under the terms of the Creative Commons Attribution Non-Commercial License (http://creativecommons.org/licenses/by-nc/3.0/) which permits unrestricted, non-commercial use, distribution and reproduction in any medium, provided the work is properly cited. 